\title{
Time for a New EU Regulatory Framework for GM Crops?
}

\author{
Charlotta Zetterberg $^{1}$ (D) Karin Edvardsson Björnberg ${ }^{2}$
}

Accepted: 6 May 2017/Published online: 20 July 2017

(C) The Author(s) 2017. This article is an open access publication

\begin{abstract}
In recent years, the EU legislation on genetically modified (GM) crops has come under severe criticism. Among the arguments are that the present legislation is inconsistent, disproportionate, obsolete from a scientific point of view, and vague in terms of its scope. In this paper, the EU GM legislation (mainly the "Release Directive", 2001/18/EC) is analysed based on five proposed criteria: legal certainty, non-discrimination, proportionality, scientific adaptability, and inclusion of non-safety considerations. It is argued that the European regulatory framework does not at present satisfy the criteria of legal certainty, non-discrimination, and scientific adaptability. Two ways of reforming the present legislation toward greater accommodation of the values expressed through the proposed criteria are briefly introduced and discussed.
\end{abstract}

Keywords GM crops · Genetic engineering · EU Release directive · Legislative techniques · Legal principles · Sustainability

\section{Introduction}

The legislative work on the use of genetic engineering in plant breeding has developed in roughly two parallel directions, or tracks. One track is "process based", which means that the technology of genetic engineering (modification) is used as a trigger for regulatory oversight. The result is a separate legislative scheme for genetically modified (GM) varieties, where a crucial factor is the way in

Charlotta Zetterberg

charlotta.zetterberg@jur.uu.se

1 Faculty of Law, Uppsala Universitet, Box 512, 75120 Uppsala, Sweden

2 Division of Philosophy, Royal Institute of Technology, KTH, Stockholm, Sweden 
which genetic engineering is framed and defined. This legislative track is followed by, for example, the European Union and its Member States. A basic tenet of the present European GM legislation is the belief that genetic modification as such needs to be regulated and controlled irrespective of the risks that individual varieties may involve. Thus, EU Directive 2001/18/EC ("Release Directive") and Regulation 2003/1829 ("Food and Feed Regulation") have licensing requirements that must be met before a GM variety can be released into the environment or put on the market. ${ }^{1}$

The second track, embraced most consistently by Canada but also to a significant extent by the United States, is "product based" (or "phenotype based"), which means that it is the organism's physical or biochemical characteristics, as determined by both genetic makeup and environmental influences, that decides which legal demands and measures need to be met or taken in order for a release permit to be granted (McHughen and Smyth 2008; Smyth and McHughen 2008; Macdonald 2014; cf. Camacho et al. 2014). ${ }^{2}$ Thus, Canadian legislation targets "plants with new traits", that is, plants containing traits that are both new to the Canadian environment and have the potential to significantly impact on the environment or human health. The traits can be introduced by genetic modification or conventional breeding techniques. The U.S. Coordinated Framework for Regulation of Biotechnology (1986) assumes that biotechnological applications are "substantially equivalent" to their non-GM counterparts and therefore do not warrant special regulatory scrutiny (Millstone et al. 1999; Levidow, Murphy and Carr 2007).

Both the EU and the North-American legislation have been criticized in literature. The European dual-track solution, with different sets of legal requirements applying to GM and non-GM varieties, has been criticized for being inconsistent and obsolete from a scientific point of view, since the potential harms caused by the introduction of GM varieties could likewise be brought about by introductions of their non-GM counterparts (Bradford et al. 2005; McHughen 2007; Miller 2010; Morris and Spillane 2010; Heap 2013; Marchant and Stevens 2015). Concern has also been voiced about the cumbersome assessment process associated with GM introductions and the negative consequences it has for innovation and economic survival of small businesses within the union (Masip et al. 2013; ACRE $2013 b$ ). From a risk perspective it has been argued that the potential negative environmental and health impacts of GM crop introductions are so small that they do not prompt special legal treatment (Giddings et al. 2012). The North-American legislation, on the other hand, has been criticized for not paying sufficient attention to the process-related preferences of consumers, for being insufficiently transparent and techno-reductive in the sense that only scientific arguments are perceived to be legitimate concerns in the regulatory process, and for failing to provide opportunities for public participation in the approval process (Pouteau 2002; Kysar 2004;

\footnotetext{
${ }^{1}$ Directive 2001/18/EC of the European Parliament and of the Council of 12 March 2001 on the deliberate release into the environment of genetically modified organisms and repealing Council Directive 90/220/EEC-Commission Declaration, OJ L 106/1. Regulation 2003/1829 of the European Parliament and of the Council of 22 September on genetically modified food and feed, OJ L 268/1.

2 See Marchant and Stevens (2015) for a discussion of the extent to which the U.S. legislation can be said to be "product-based".
} 
Du 2012). Moreover, the notion of "substantive equivalence" upon which the system rests has been criticized for being vague, unscientific, and biased (Millstone et al. 1999; Sagers and Finlay 2013). ${ }^{3}$

Given the diverging views that exist on the strengths and weaknesses of the two legislative techniques it is interesting to investigate to what degree they manage to accommodate some legal principles and criteria that we believe legislation would minimally have to satisfy. Our focus will be on GM crops and the present European GM legislation. In "What Legal Principles and Criteria Should a Regulatory Framework for GMOs Meet?" section, based on a survey of the regulatory literature on GMOs, we devise a first non-exhaustive and partially overlapping set of such principles and criteria: (i) legal certainty (i.e., the regulatory system is precise and understandable and its legal implications foreseeable), (ii) non-discrimination (i.e., the system treats similar varieties/risks in a similar way), (iii) proportionality (i.e., the system does not exceed what is necessary to achieve the objectives of the system), (iv) scientific adaptability (i.e., the system is flexible enough to take the latest scientific findings into account), and (v) inclusion of non-safety considerations (i.e., the system allows for socioeconomic, ethical, religious, aesthetic, et cetera, aspects to be considered as part of the approval procedure). In "Legal Certainty", "Non-discrimination and Coherence with Non-GM Breeding Techniques", "Proportionality", "Scientific Adaptability" and "Inclusion of Non-safety Criteria" sections, we assess the present EU legislation based on the chosen principles and criteria. In order to make visible the main strengths and weaknesses of the EU legislation, we make comparisons with how GM introductions are regulated in Canada and the US. In "Ways of reforming the present EU legislation" section, we summarize the results of our legislative comparison. Based on the identified shortcomings we tentatively outline two possible ways of reforming the present EU GM legislation that we believe deserve further scholarly attention. "Conclusions" section contains our conclusions.

Admittedly, designing a regulatory system that is evidence-based in the sense that it takes into account the latest scientific findings, regulates risk proportionally and consistently, captures the central ethical issues at stake, and enjoys a high degree of legitimacy and public support is a complex task that would require the involvement of specialists, not only from the legal field but crop and animal breeding, political science, economics, philosophy of risk and related disciplines. Therefore, the proposals outlined towards the end of the paper should be regarded as a first tentative contribution towards the on-going debate about how GM crop introductions should be regulated within the EU.

\footnotetext{
3 The concept of "substantive equivalence" was introduced in 1993 by the Organization of Economic Cooperation and Development (OECD) (Millstone et al. 1999). In a report from that year, the organization explicates the concept of "substantial equivalence" as embodying "the idea that existing organisms used as food, or as a source of food, can be used as a basis for comparison when assessing the safety of human consumption of a food or food component that has been modified or is new" (OECD 1993, p. 14). The concept is abandoned within EU in respect of genetically modified food, cf. recital 6 in the Food and Feed Regulation.
} 


\section{What Legal Principles and Criteria Should a Regulatory Framework for GMOs Meet?}

In this section, based on what has been proposed in the GMO regulation literature to date, we identify a non-exhaustive set of legal principles and criteria of relevance that we believe any reformed EU GM regulatory system would have to meet. By "legal principles" we mean rules or standards of a general kind that, whether codified or not, have to be followed by legislators and decision-makers in one way or another. They are of various kinds; some principles have substantive effects, others guide procedures; some aim at protecting individual rights, others at protecting common values. However, what unites them is that they are usually of great importance as legal sources and that it is common to use them as a point of departure when analyzing law interpretations and applications in practice (Marcusson 2012). In this paper, they will primarily be used to analyze the design of the present EU GM legislation (i.e., the legal acts themselves), rather than interpretations and applications of the legislation, for example in the form of legal rulings.

\section{Legal Certainty, Non-discrimination, Proportionality and Scientific Adaptability}

Drawing on literature in the field, it could be argued that regulations in the food and feed areas should minimally satisfy four legal principles and criteria: legal certainty, non-discrimination, proportionality, and scientific adaptability.

The principle of legal certainty is a well-established principle in EU law as well as international and public law. It requires that the law is precise and understandable and that its implications are foreseeable by those to whom it applies. A major criticism against the EU GM legislation is that it fails to meet the principle of legal certainty, since it is at present (autumn 2016) unclear whether plants developed through new breeding techniques (NBTs) should count as genetically modified organisms in accordance with the definition provided in the Release Directive. We will return to this argument in "Legal Certainty" section.

The principle of non-discrimination essentially requires that "comparable situations should not be treated differently" (Morris 2007, p. 5); specifically in a GM context, like risks should be treated alike. One of the most persistent arguments against the present European GM legislation is that it violates the requirement of non-discrimination, since although GM varieties could be phenotypically identical to conventionally bred varieties they are subject to much more stringent regulation. Thus, the precautionary principle upon which EU environmental law (including the Release Directive) is based is not consistently applied in the case of new crop introductions. We will return to this argument in "Non-discrimination and coherence with non-GM breeding techniques" section.

The proportionality principle gives the government the right to exercise its power against the citizens in pursuit of a public interest (e.g., protection of human health or the environment) if the measures taken are effective, necessary, and balanced (Winter 2013; see also Jans and Vedder 2012). The principle thus requires that the 
rights of citizens must never be violated by the government unless the objectives pursued are justifiable and the legislative measures (means) taken to achieve those objectives satisfy certain criteria (the means must be capable of serving the public interest, must not be replaceable by measures that are equally effective but less intrusive, and not excessively intrusive in the light of the pursued objectives) (Winter 2013).

The proportionality principle is enshrined in Article 5(4) of the Treaty on the European Union, which states that "the content and form of Union action shall not exceed what is necessary to achieve the objectives of the Treaties". The primary objectives of the EU GM legislation are to protect human health and the environment (including animal health and welfare), and the legislator has chosen to pursue these objectives by restricting a private interest, namely the freedom of cultivation/trade. ${ }^{4}$ The proportionality-related criticism mounted against the legislation amounts to questioning whether the Release Directive and the other legal acts are indeed appropriate (effective, necessary and balanced) in order to reach the adopted objectives. We will return to this argument in "Proportionality" section.

Scientific adaptability means that the regulatory system allows for the latest scientific findings on emergence of new hazards, changes in technology, new evidence on risk, et cetera, to be taken into account (Jaffe 2004; Riviere and Buckley 2012). The criterion of scientific adaptability can be seen as a refinement of the principles of non-discrimination and proportionality in that a regulatory system that is not flexible enough to take the latest scientific findings into account seldom has the capacity to regulate risk in a non-discriminatory and proportionate way. A common argument against the EU GM legislation is that it is outdated from a scientific point of view since it uses certain production techniques rather than the individual traits and the risk they give rise to as a trigger for regulatory oversight. By tying the risk assessment process to specific production techniques it becomes difficult to adjust to new scientific evidence concerning the actual risks of GM introductions. We will return to this argument in "Scientific Adaptability" section.

As with legal principles and criteria in general one should keep in mind that the four principles and criteria used as analytic framework in this paper cannot really be discussed in isolation. To some extent the principles and criteria overlap (as indicated above) and in many cases they need to be balanced against one another or against other principles. For example, the principle of proportionality sometimes has to be balanced against the precautionary principle, and the criterion of scientific adaptability against legal certainty and predictability (Ebbesson 2009). However, for systematic reasons we discuss the principles and criteria under separate headings below.

\footnotetext{
4 Article 1 of the Release Directive states that "In accordance with the precautionary principle, the objective of this Directive is to [...] protect human health and the environment". The objectives of the Food and Feed regulation are broader. Article 1 of the regulation states that "The objectives of this Regulation [...] is to provide the basis for ensuring a high level of protection of human life and health, animal health and welfare, environment and consumer interests in relation to genetically modified food and feed, whilst ensuring the effective functioning of the internal market".
} 


\section{Inclusion of Non-safety Considerations}

In addition to providing protection against environmental and human health hazards, it could be argued that regulations in the food and feed areas should be normative legitimate. That is, they should be responsive to people's political, ethical, and religious beliefs and preferences concerning food production, retailing and marketing (Kysar 2004; McHughen 2007). One way of achieving normative legitimacy is to allow for non-risk related aspects to be part of the GM approval procedure (Du 2012; see also Marchant, Meyer and Scanlon 2010), for example by supplementing the environmental and health risk assessment with an ethical assessment or a broader socioeconomic impact assessment. In this paper, the term "non-safety considerations" will be used to denote such non-risk related aspects. ${ }^{5}$ A number of legislations presently in force allow for non-safety considerations to play a role in the GM approval process, including Norway, Sweden, and Argentina (Falck-Zepeda 2009; Marcoux, Cardenas Gomez and Létourneau 2013).

Whether or not non-safety considerations should be part of the approval process for GM varieties is a controversial issue. A common argument against the inclusion of non-safety considerations is that they may render the GM approval process more indiscriminate and less scientifically grounded. On this view, non-safety effects are much harder to define and quantify than health and environmental impacts; they are seldom fixed in time but tend to shift depending on how societies evolve; and are ultimately something that people will have very different views on (see discussion in Marchant, Meyer and Scanlon 2010).

However, inclusion of non-safety considerations could be argued for on both normative and instrumental grounds. Perhaps the most obvious normative argument in support of inclusion of such aspects, as indicated above, relates to the purported rights of members of a liberal society to raise social, ethical, religious, et cetera, concerns about decisions made by the government, and to have those concerns addressed by governmental decision makers (Marchant, Meyer and Scanlon 2010). It is an empirical fact that people have preferences over manufacturing processes; they care about how food and feed are produced, as evidenced by, for example, the Fairtrade and other social movements. Arguably, if there is reason to believe that those preferences are well-informed in the sense that they are not based on misunderstandings of the science underpinning genetic modification or what is presently known about the potential social, environmental and health consequences of GM introductions, they should not be dismissed categorically by the legislator (Kysar 2004).

To further strengthen this line of argumentation, one could point to the effects that an inclusion of non-safety considerations could have in terms of people's trust in the GM regulatory system. If recognition of people's preferences over food and feed manufacturing processes and the broader socioeconomic impacts of GM

\footnotetext{
5 The term "non-safety considerations" refers to many different non-risk related aspects of GM crop introductions, such as ethical and religious aspects (e.g. naturalness, animal welfare, justice, and consumer autonomy), aesthetic aspects, and socioeconomic aspects (e.g. effects on farm incomes, rural employment, trade and competition, cultural heritage, and food security) (Falck-Zepeda and Zambrano 2011; Ludlow, Smyth and Falck-Zepeda 2014).
} 
introductions can help to further trust in the regulators and the decisions taken by them, then this would serve as an additional reason for including such considerations in the GM approval process. Empirical evidence from the psychological and economic sciences suggests that giving the public a voice in the GM approval process might indeed have such an effect (see Kysar 2004, p. 604ff. and references therein).

There is in addition a more principled objection to the argument that exclusion of non-safety considerations will make the GM approval process more objective from a scientific point of view. As indicated above, environmental and health risk assessment is often perceived to be a strictly scientific and value-neutral exercise. However, it is vital to remember that values are an inherent part of the scientific enterprise, as well as the risk assessment process itself. Values can, for example, influence both the risk selection process (what risks to look at) and how evidence concerning risk is assessed. To take one example, Douglas (2009) mentions the case of chemical risk assessment, in which one often has to extrapolate from high experimental doses given to lab animals to low environmental doses to which humans are exposed. There are many different extrapolation methods available, and the choice of method often involves a value judgement concerning what should count as sufficient evidence. Du (2012) follows a similar line of argumentation when she contends that even if value judgments are not explicitly included in the GM approval process they very often sneak in through the backdoor:

Non-scientific value judgments are embedded within science and technology regulation to a greater extent than we frequently realize. For example, "safety" concerns require regulators to look outside of the realm of scientific facts for indicators of acceptability and adequate protection because the degree of acceptable risk is ultimately a non-scientific question of culture, values, and priorities. (Du 2012, p. 391).

Therefore, instead of creating the impression of an entirely value-neutral and scientifically objective GM risk assessment process by rejecting non-safety considerations altogether, it appears to be much more intellectually honest to explicitly recognize that such considerations are, at least to some extent, already part of the GM approval process. This could lead to increased transparency, greater accountability on behalf of the political decision makers, and again, increased levels of public trust in the regulatory system.

However, exactly how non-safety considerations should best be incorporated into the GM approval procedure remains to be investigated. There is a risk that by allowing for non-safety considerations the government could "end up sacrificing truth for legitimacy in an attempt to win public trust" (Du 2012, p. 398). If people's preferences are ill-informed in the sense that they are based on false and misleading beliefs about the scientific underpinnings of genetic engineering, they could easily be exploited by interest groups who wish to further their own interests in certain forms of production or life styles (Kysar 2004). This could lead to perfectly safe and beneficial GM varieties not being commercialized, and for no good reasons. Therefore, the ways in which non-safety considerations are incorporated into the 
approval procedure will have to be scrutinized carefully. That, however, is a question that lies beyond the scope of this paper.

Admittedly, by postulating that non-safety should be part of the approval process we take a stance on this controversial issue. The reason why non-safety considerations are still included in our analysis is not only that they enjoy some normative support and, therefore, enriches our legal analysis. It is also plausible to assume that a reformed EU regulatory framework for GMOs would have to make room for non-safety considerations in order to constitute a feasible policy alternative. The recent addition of Article 26b to the Release Directive, decided by the European Parliament indeed suggests that non-safety considerations will play an even greater role in decision making by the EU Member States in the future. ${ }^{6}$

\section{Legal Certainty}

A major point of criticism that has been mounted against the EU GM legislation concerns its indeterminate scope. Article 2(2) of the Release Directive defines a GMO as "an organism with the exception of human beings, in which the genetic material has been altered in a way that does not occur naturally by mating and/or natural recombination". 7 Within the terms of this definition genetic modification occurs at least through the use of the techniques listed in Annex I A, part 1, namely inter alia:

1. recombinant nucleic acid techniques involving the formation of new combinations of genetic material by the insertion of nucleic acid molecules produced by whatever means outside an organism, into any virus, bacterial plasmid or other vector system and their incorporation into a host organism in which they do not naturally occur but in which they are capable of continued propagation;

2. techniques involving the direct introduction into an organism of heritable material prepared outside the organism including micro-injection, macro-injection and micro-encapsulation;

3. cell fusion (including protoplast fusion) or hybridization techniques where live cells with new combinations of heritable genetic material are formed through the fusion of two or more cells by means of methods that do not occur naturally.

As the terms "at least" and "inter alia" reveal, the Release Directive allows for additional techniques to the ones mentioned in the present section to be considered resulting in a GMO. The general scope of the directive can thus be said to be wide and non-exhaustively defined. At the same time, the directive allows for a number of precisely formulated exceptions. Annex I A, part 2 explicitly excludes in vitro

\footnotetext{
${ }^{6}$ Directive 2015/412 of the European Parliament and of the Council of 11 March 2015 amending Directive 2001/18/EC as regards the possibility for the Member States to restrict or prohibit the cultivation of genetically modified organisms (GMOs) in their territory, OJ L 68/1.

7 The Food and Feed regulation (Article 2) defines GMO in the same way by referring to the Release Directive. However, the scope of the regulation is furthermore restricted to genetically modified food and feed, that is, food or feed containing, consisting of, or produced from GMOs (Article 3).
} 
fertilisation, natural processes (such as conjugation, transduction and transformation), and polyploidy induction, on condition that they do not involve the use of recombinant nucleic acid molecules or genetically modified organisms made by techniques methods other than those excluded in Annex I B. Annex I B explicitly excludes mutagenesis and cell fusion, including protoplast fusion, of plant cells of organisms which can exchange genetic material through traditional breeding methods.

A number of new breeding techniques (NBTs) have been developed since the enactment of the EU legislation in the early 2000s. Site-directed nuclease (SDN), cisgenesis, and RNA-dependent DNA methylation are three examples. At present, these techniques are stuck in a legal limbo within the EU system, since it is uncertain whether they should fall within the general scope of the legislation (which a literal reading of the Release Directive appears to support) or be part of the list of techniques explicitly excluded from oversight (Hartung and Schiemann 2014; Abbott 2015). Pending a policy decision by the EU Commission on the NBTs some Member States have unilaterally decided to exempt some varieties developed by the use of some NBTs from oversight. For example, in spring 2016 the Swedish Agricultural Board decided that a new variety that had been developed by using CRISPR-Cas9 should not count as a genetically modified organism. ${ }^{8}$ Because of the uncertain legal status of CRISPR/Cas9 and other breeding techniques the EU GM legislation does not meet the principle of legal certainty at present. This is unsatisfactory, not only because it threatens to stifle innovation and investment within the EU (Jones 2015); it could in addition lead to loss of valuable knowledge and resources, as plant breeding specialists increasingly look to go abroad to continue their research. It could of course be objected that, once a decision has been reached by the Commission concerning the status of the NBTs currently under investigation, everybody will know which techniques fall within the scope of the directive and legal certainty will, thus, be restored. However, other NBTs will likely be developed in the future in which case the problem of legal uncertainty resurfaces. There is, in other words, an inherent vulnerability in a legal construction that regulates risk based on the use of a specific technology and where the boundaries of the technology are in need of continuous re-definition due to rapid advancement in science. This point will be further elaborated on in "Scientific Adaptability" section.

It could be argued that one way of avoiding this problem is to adopt a productbased legislation that is based on the notion of substantial equivalence. In Canada, only "plants with novel traits" (PNTs) are subject to regulatory scrutiny (Smyth and McHughen 2008). PNTs are plants that contain traits that are new to the Canadian environment and have the potential to significantly impact on the environment or human health. To enter the market, PNTs must undergo stringent assessment, which aims to ensure that the plant is as safe as the conventional plants already in use (Marchant and Stevens 2015). Since the legislation applies to all varieties with

\footnotetext{
8 http://www.slu.se/en/about-slu/fristaende-sidor-eng/whats-on/news/2015/11/green-light-in-the-tunnelopinion-of-the-swedish-board-of-agriculture-a-crispr-cas9-mutant-but-not-a-gmo/ (accessed 17.05.2016).
} 
novel traits, regardless of breeding method, it can be said to provide greater legal certainty than the present EU legislation.

In the United States, the rules cover introductions of so-called "regulated articles". Regulated articles are organisms or products altered or produced through genetic engineering, which are plant pests or at least there is reason to suspect that they are. ${ }^{9}$ Genetic engineering is defined as genetic modification of organisms by recombinant DNA techniques. The U.S. legislation on plant pests aims to determine the extent to which an organism can harm plants, or parts thereof, directly or indirectly; the aim is not to protect ecosystems. Furthermore, there is a risk that the U.S. product based legislation, consisting of many different legal acts, will not be comprehensive and that some GM varieties will remain unregulated (Czarnezki and Montgomery 2013). To take one example, if a GM crop is not classified as a "plant pest" according to the US GM legislation, there is no other piece of legislation that enters into force and the crop will remain unregulated (Kimbrell 2013). ${ }^{10}$

\section{Non-discrimination and Coherence with Non-GM Breeding Techniques}

A second major point of criticism against the EU GM legislation is that it violates the principle of non-discrimination, since it puts severe restrictions on (GM) varieties that fall under the directive but fails to regulate (conventional, non-GM) varieties that involve similar or in some cases even more serious risks (McHughen 2007; Morris 2007; Morris and Spillane 2010; Podevin et al. 2012; ACRE 2013a). ${ }^{11}$ Batista et al. (2008) mention the example of plant mutagenesis, which does not fall under the present legislation but which could induce much more transcriptomic changes than transgene insertion. Arguably, if the health and environmental risks associated with GM crop introductions are the same in kind as those associated with conventional varieties, there are no good reasons for maintaining separate legislations for GM and conventional varieties from the viewpoint of health and environmental risk prevention (NIH 1992; Miller 2010).

\footnotetext{
9 A regulated article is "any organism which has been altered or produced through genetic engineering, if the donor organism, recipient organism, or vector or vector agent belongs to any genera or taxa designated in $\$ 340.2$ and meets the definition of plant pest, or is an unclassified organism and/or an organism whose classification is unknown, or any product which contain such an organism or any other organism or product altered or produced through genetic engineering which the Administrator, determines is a plant pest or has reason to believe is a plant pest." A plant pest is "Any living stage (including active and dormant forms) of insects, mites, nematodes, slugs, snails, protozoa, or other invertebrate animals, bacteria, fungi, other parasitic plants or reproductive parts thereof; viruses; or any organisms similar to or allied with any of the foregoing; or any infectious agents or substances, which can directly or indirectly injure or cause disease or damage in or to any plants or parts thereof, or any processed, manufactured, or other products of plants.", 7 CFR Part 340.1.

10 If a GM crop is classified as a "plant pest" an applicant may petition for deregulation.

11 As noted by Morris and Spillane (2010), this objection was raised by a number of scientists already prior to the adoption of the present EU GM legislation. In the minutes from the 40th meeting of the Council of the European Molecular Biology Organization (EMBO) the organization expressed the opinion that " $[\mathrm{t}]$ here is no scientific justification for additional specific legislation regulating recombinant research per se".
} 
From the viewpoint of "risk consistency" a product-based legislation is preferable. Since the legislation uses an organism's phenotype instead of a particular technology as a trigger for regulatory oversight, it can be applied more consistently to the real risks of GM introductions (McHughen 2007; Heap 2013). It can of course be objected that the product-based legislations presently in force have a too limited view on what risks should be taken into account in the approval process. For example, in the United States where the U.S. Animal and Plant Health Inspection Service (APHIS) is responsible for protecting U.S. agriculture from pests and diseases the scope of the risk assessment in the U.S. APHIS notification procedure is limited to include only direct and immediate effects. ${ }^{12}$ On the other hand, in the APHIS authorization procedure, an Environmental assessment (EA) may be required when a release of a GM organism or product "involves new species or organisms or novel modifications that raise new issues". ${ }^{13}$ If a Threatened and Endangered Species or NEPA analysis will be required, the analysis must consider both the direct (immediate) and indirect (later in time, but reasonably certain to occur) effects. ${ }^{14}$ However, the large majority of applications involving plant species are for notifications and not permits and, thus, do not include assessment of indirect and delayed effects (Kimbrell 2013).

This is to be contrasted with the Release Directive according to which a case-bycase risk analysis shall describe direct, indirect, immediate, and delayed effects. The applicant's obligation is comprehensive, since also analysis of cumulative long-term effects is to be carried out. ${ }^{15}$ It could be argued that by refraining from assessing indirect and delayed effects, the U.S. GM risk assessment process is incomplete and does not adequately protect human health or the environment. However, whether the scope of the risk assessment process is wide enough to provide sufficient protection against harm to human health or the environment is a separate question to whether or not the risks of GM and non-GM introductions are consistently regulated. The risks of GM and non-GM introductions can be consistently regulated, in which case the legislation would satisfy the criterion of non-discrimination; however, the argument can still be made that the scope of the risk assessment protocol used is too narrow to protect human health or the environment to a sufficient degree.

\footnotetext{
12 See 7 CFR 340.3(b) and USDA-APHIS Biotechnology Regulatory Services User Guide Notification v. 03/29/2011.

137 CFR 372.5(d)(4).

14 USDA-APHIS Biotechnology Regulatory Services Permit User's Guide With Special Guidance for ePermits, v. 5/30/2012, p. 38, Appendix A, p. 3.

15 That is, "the accumulated effects of consents on human health and the environment, including inter alia flora and fauna, soil fertility, soil degradation of organic material, the feed/food chain, biological diversity, animal health and resistance problems in relation to antibiotics", see Article 4, 6 and annex II and III (deliberate release) and article 2 (8), 4, (2) and 13 as well as annexes II, III and IV (placing on the market). Although the Release Directive in many ways reflects the precautionary principle and have a relatively high level of ambition with regard to the requirement to investigate risks, it has been criticized for a series of shortcomings. For example, von Kries and Winter (2012, p. 573) mention the lack of landscape perspective and the lack of in-depth analysis on the molecular and cellular levels (see also Then 2013).
} 


\section{Proportionality}

The proportionality principle requires that the legal measures specified in the GM legislation are suitable and necessary to achieve the objectives of the legislation. As noted above, the primary objectives of the Release Directive are, in accordance with the precautionary principle, to protect human health and the environment as well as to approximate the laws. ${ }^{16}$ The directive includes references to other values, such as "respect for ethical principles recognized in a Member State" (recital 9) and "socioeconomic advantages and disadvantages" (recital 62); however, they are not expressed as objectives in Article 1 of the directive. ${ }^{17}$ The precautionary measures specified in the directive include conducting an environmental risk assessment before any experimental release of a genetically modified variety takes place, taking safety measures once a genetically modified variety has been released, and various notification and labelling requirements. One of the central arguments against the present EU legislation is that the required measures do not meet the requirement of proportionality, since they do not constitute an effective, necessary or balanced means of protecting human health and the environment (Podevin et al. 2012; Riviere and Buckley 2012). Below, each of the preconditions of the proportionality principle will be used to analyse the Release Directive in greater detail. For the sake of the argument it will be assumed that the objectives pursued through the directive are justifiable, and that the first precondition of the proportionality principle is thus met.

First of all, the proportionality principle requires that the precautionary measures specified in the directive are effective in the sense that they are capable of serving the public interest (in this case protection of human health and the environment). Arguably, by subjecting new GM varieties to extensive risk assessment and other safety measures the probability of harm to the environment and human health caused by such introductions is indeed significantly reduced. However, it could be disputed whether the precautionary measures prescribed by the directive reduce the overall risks to human health and the environment. It could be argued that the present legislation fails to satisfy the criterion of effectiveness, since there is reason to believe that (at least some) GM crops, because of their genetically modified traits, could have a much less negative impact on the adopted objectives than their conventional counterparts. To the extent that this holds, the precautionary measures required by the directive in order to safeguard human health or the environment do not meet the criterion of effectiveness.

Second, the proportionality principle requires that the precautionary measures are necessary in the sense that they cannot be replaced by alternatives that are equally effective but less intrusive on individual rights. Here, at least two lines of argumentation are possible. First, it could be argued that since the risks associated

\footnotetext{
16 "Approximate the laws" means that the Member States must align their national laws, rules and procedures in order to give effect to the Directive.

17 See also recitals (57), (58) and (60) in the preamble and Articles 26b, 29 and 31. The Food and Feed Regulation embraces broader objectives such as protection of animal health and welfare and consumers interests. Since our focus is on GM crops we will restrict our analysis of the proportionality principle to the objectives of the Release Directive.
} 
with GM introductions are close to zero, virtually no precautionary measures can ever qualify as necessary in the sense that they cannot be replaced by alternatives that are less intrusive on individual rights. Consequently, the precautionary measures required by the present legislation do not satisfy the proportionality principle. Furthermore, even if one agrees that the risks of GM introductions are much larger, one can still question whether there is a need for the precautionary measures prescribed, for example, by the Release Directive. Perhaps an equal level of protection could be achieved through a different legislative technique, say a product-based legislation.

Let us look deeper into this argument. There are good reasons to believe that a product-based regulatory framework, such as the Canadian, is less intrusive on the freedom of cultivation/trade than the EU legislation, since it only regulates introductions of varieties with "novel traits". As long as the variety does not contain any such traits, farmers are free to cultivate it without any further safety measures having to be taken. If the Canadian legislation is, in addition, equally effective in preventing harm to human health and the environment as the EU legislation, it satisfies the proportionality principle to a greater degree than its European counterpart. However, the key question is whether the legislation does in fact provide equal protection. That question is very difficult to answer, not only because a meaningful comparison would require empirical investigations into the policyoutcome relationship in the two jurisdictions under consideration; it also depends on how the objectives of the legislations under consideration are interpreted. Both the Canadian and the EU legislation aim at protecting human health and the environment. However, since the EU, but not the Canadian, legislation is based on the precautionary principle, the acceptable level of risk may differ between the two, which in turn affects the proportionality assessment. ${ }^{18}$

Finally, the proportionality principle requires that the precautionary measures are balanced in the sense that they do not intrude on individual rights to a greater degree than what is justified given the importance of the objectives pursued. This involves balancing the public interest (protection of human health and the environment) against a private interest (freedom of cultivation and trade). Since such a balancing would require a much more developed argumentation than can be offered in this paper, it will not be dealt with further here.

\section{Scientific Adaptability}

As suggested above, a central point of criticism against the EU GM legislation concerns the inability of the legislation to take into account new evidence concerning the environmental and health risks associated with GM crop

\footnotetext{
18 See TFEU, Article 191. In EU law the precautionary principle is defined in the following way: "If there is the possibility that a given policy or action might cause harm to the public or the environment and if there is still no scientific consensus on the issue, the policy or action in question should not be pursued", see EUR-Lex, Glossary of summaries, entry"Precautionary Principle", available from: http:// eur-lex.europa.eu/summary/glossary/precautionary_principle.html (accessed 25.2.2016). See also Communication from the Commission on the precautionary principle, COM (2000) 1 final of 2 February 2000.
} 
introductions. There are a number of provisions in the Release Directive dealing with the achievement of new information. ${ }^{19}$ Most provisions require that, if new information regarding the risks of GMOs becomes available, the notifier (the applicant) should act upon that information (i.e., take precautionary action) and inform the competent authority thereof. There is nothing in the information rules explicitly preventing that they could also be applied in situations in which new information about lesser human health or environmental risks of GM crops emerges. However, the formulations of the provisions together with the general framing of the directive, with its explicit ambition to achieve a high level of protection, make it clear that they are directed at situations where the risks turn out to be graver than initially believed. This information asymmetry is perhaps most obvious in Articles 20 and 23 of the Release Directive:

If new information has become available, from the users or other sources, with regard to the risks of the GMO(s) to human health or the environment after the written consent has been given, the notifier shall immediately take the measures necessary to protect human health and the environment, and inform the competent authority thereof. (Article 20(2)).
Where a Member State, as a result of new or additional information [...] affecting the environmental risk assessment or reassessment of existing information on the basis of new or additional scientific knowledge has detailed ground for considering that a GMO [...] constitutes a risk to human health or the environment, that Member State may provisionally restrict or prohibit the use and/or sale of that GMO [...]. (Article 23(1))

Since the provisions do not explicitly cover situations in which new scientific evidence has emerged to the effect that an assessed GMO is less risky than previously thought, the EU regulation could be criticized for failing to meet the criterion of scientific adaptability. ${ }^{20}$

Arguably, there is greater room for accommodating the value of scientific adaptability in a product-based system. The U.S. legislation has certain flexibility in that a GM variety can be listed as a plant pest, and thus be more stringently regulated, as well as removed from the list as new information comes to light. ${ }^{21}$ Furthermore, any person may submit a petition to APHIS to seek a determination that a regulated article should have a "non-regulated status". ${ }^{22}$ If the authority determines that the regulated article does not present a risk of introduction or dissemination of a plant pest, the petition will be granted, thereby allowing unrestricted introduction of the article. Before the assessment, the applicant must provide information on, inter alia, deleterious effects on non-target organisms and

\footnotetext{
${ }^{19}$ See Articles 6(7), 8, 13(6), 17(2c), 20(2-3), 23 and Annex II B.

${ }^{20}$ In addition, despite the many provisions in the directive dealing with the collection of new information, the directive's ability to support the production of new knowledge has been questioned. Valve and Kauppila (2008) argue that this knowledge risks to be standardized since applicants are not motivated to generate new knowledge and are likely to make very similar findings.

217 CFR 340.2 and 7 CFR 340.5.

227 CFR 340.6.
} 
environment from field releases. ${ }^{23}$ Depending on the risk picture the decision will be preceded by various investigations, such as an Environmental Assessment declaring a "Finding of no significant impacts" 24 or the more ambitious Environmental Impact Statement (EIS). APHIS may also extend a determination of non-regulated status to additional regulated articles, upon finding that those articles do not pose a plant pest risk, and should therefore not be regulated (a similarity test) ${ }^{25}$ Thus, there is much greater room in the U.S. than in Europe for adjusting the GM legislation to new scientific findings.

\section{Inclusion of Non-safety Criteria}

As noted above, the primary objective of the Release Directive is to protect human health and the environment. There is no explicit requirement that a Member State take non-safety considerations into account in its approval process, although recital 9 of the directive allows for such aspects to be part of the approval process. It is, however, uncertain to what extent the Member States can in fact take ethical, religious or socioeconomic aspects into consideration in their national approval processes. The directive is market-based and contains a free trade clause, which all Member States have to follow. Moreover, the right to take ethical, religious or socioeconomic aspects into account is not clearly reflected as substantive standards in the operative articles, but merely mentioned in relation to the Commission's duty to seek advice on the ethical implications of biotechnology and submit reports to the European Parliament and Council.

From a legal point of view, it is not entirely clear-cut what should count as an ethical aspect in the context of GM crop introductions. Ethical aspects are not defined in the Release Directive, nor have they been clearly delineated by the European Court of Justice (ECJ). Some guidance can be found in the decisions made by the authorities involved in assessment of GM varieties at the national level. For example, the Swedish Gene Technology Advisory Board, which is responsible for carrying out ethical assessment of GM varieties before they can be released in Sweden, have identified a number of aspects considered to be ethical, including animal welfare, consumer autonomy, and justice in a national and global context. ${ }^{26}$

Ethical aspects have been the subject of a case in the ECJ (Case C-165/08). Poland had in its seeds legislation provisions stating "genetically modified varieties shall not be included in the national catalogue" and "the seeds of genetically

\footnotetext{
237 CFR 340.2 and 7 CFR 340.5.

24 Findings of no significant impacts is a public document issued by a Federal agency briefly presenting the reasons why an action for which the agency has prepared an environmental assessment will not have a significant effect on the human environment and therefore will not require preparation of an environmental impact assessment. In the assessment of significant effect will considerations of the importance for society as a whole as well as the effect on the individual location be taken into account. Both long-term and short-term aspects shall be taken into account, etc. 40 CFR $\$ 1508.27$.

257 CFR 340.6(e). See for example National Environmental Policy Act decision and Finding of no Significant Impact, Monsanto Company, Lepidopteran-Protected Soybean MON 87751.

26 http://www.genteknik.se/sv/etiska-bedomningar (in Swedish, accessed 21.04.2017).
} 
modified varieties cannot be accepted on the market in the territory of the Republic of Poland". Anyone who placed a GM seed on the Polish market would be imposed an economic sanction. The central question was whether the national provisions were contrary to the free trade clauses in the Release Directive and the Seeds Directive (2002/53/EC). ${ }^{27}$ Poland claimed ethical reasons of Christian and humanistic character, which were alleged to be shared by the majority of the Polish population. According to the ECJ, Poland, which had the burden of proof, was unable to show that the national provisions were based on religious and ethical grounds.

However, the possibilities for taking non-safety considerations into account have recently increased. As of 2015, through the insertion of Article 26b into the Release Directive, the EU Member States have been given a right to adopt measures restricting or prohibiting the cultivation of GMOs within their territories based on environmental or socioeconomic considerations that have not been dealt with in the environmental risk assessment process. ${ }^{28}$ The Member States are given two options: They can either demand restriction of the geographic area during the authorization procedure, or in cases where a GMO has already been approved, they may adopt measures restricting or prohibiting the cultivation of the GMO in all or part of its territory. In the former case, the Member State do not need to justify why the want it that way, although a giving reason is recommended (Winter 2015). The latter requires that certain grounds are in place. The grounds have to be in conformity with Union law, reasoned, proportional and non-discriminatory as well as compelling. The directive has a non-exhaustive list of compelling grounds in article 26b(3), among them those related to environmental policy objectives, town and country planning, socio-economic impacts, and agricultural policy objectives. The grounds must not in any case conflict with the environmental risk assessment carried out pursuant to the Release Directive or the Food and Feed Regulation, but could nevertheless be based on new scientific evidence concerning aspects not dealt with in the environmental risk assessment process, such as socioeconomic impacts, organic production, or "maintenance of local biodiversity, including certain habitats and ecosystems, or certain types of natural and landscape features, as well as specific ecosystem functions and services". ${ }^{29}$ The list of compelling grounds is nonexhaustive and may include ethical or religious grounds, such as respect for nature, "recognition of a plant's genuine character", and "reverence for the Creation" (Winter 2016, p. 130). According to Winter (2016), and in the light of the abovementioned ECJ case, there are indications that in case of a renewed referral of the

\footnotetext{
27 Council directive 2002/53/EC of 13 June 2002 on the common catalogue of varieties of agricultural plant species, OJ L 193/1.

28 See Directive 2015/412 which amends the Release Directive by adding two new articles, Article 26b and Article 26c. To some extent there already exists an opportunity to restrict in all or in part of the territory already existing for GM varieties where Member States have valid reasons that the variety presents a risk for human health or the environment. See article 16, p. 2, the Seeds directive and Case C-36/11 Pioneer, OJ C 355/5. See also article 2.2. of the Treaty of the Functioning of European Union. According to de Sadeleer (2015), this is the first time in history of the internal market that there has been a reverse harmonization, "as the freedom to use an authorised product, for which free movement is guaranteed, is now regulated by the national authorities" (p. 557).
}

29 Directive 2015/412, preamble, recital 14. See further Winter (2016). 
question of ethical grounds to the ECJ, the court would grant them an appropriate role.

In the U.S. product-based legislation and praxis, there are no inclusions of nonsafety considerations. None of the eligibility criteria mentioned above or performance standards require that socioeconomic or ethical considerations be taken into account in the approval process.

\section{Ways of Reforming the Present EU Legislation}

From our analysis above it seems that the present EU legislation does not meet the criteria of legal certainty, non-discrimination, and scientific adaptability. Further analysis is needed in order to answer to what extent it satisfies the criterion of proportionality. In what ways, then, could the present EU framework for GM varieties be reformed so that it better satisfies the principles and criteria of legal certainty, non-discrimination, and scientific adaptability, while at the same time taking non-safety considerations into account? Below, we briefly discuss two ways of reforming the present EU framework toward greater accommodation of the values expressed through these principles and criteria. They both, in different ways, constitute a regulatory shift for GM varieties within the union.

\section{A New Protocol for Risk Assessment}

A first route towards regulatory reform could be to retain a separate regulatory track for GM varieties (thus signaling that more thorough risk assessment might be required for GM varieties than for conventional varieties) but incorporate selected aspects of a product-based legislation into the legislation. This could for instance be done by reforming the risk assessment protocol presently in force so that it is based on the traits and gene functions, rather than merely on the method used to introduce the trait. One way of doing this is through a stratification procedure where different GM varieties are categorized as "low", "medium", or "high risk" (Bradford et al. 2005; see also ACRE 2007, 2013b) depending on what is known about the variety/trait (Barton et al. 1997; see also Miller et al. 1995). For varieties that are categorized as "low risk" no further risk assessment would be required before the variety can be deliberately released through a field trial or placed on the market. For "moderate" to "high" risk varieties more stringent regulatory oversight would be needed, for example as specified in Bradford et al. (2005). The three risk classes would be based on scientific criteria such as the variety's "ability to colonize" (by outcrossing with wild relatives), "proximity to centers of origin" (outcrossing is generally considered less likely for varieties with no wild relatives in the vicinity), dynamics of pollination (e.g. vegetative propagation or sexual reproduction), and weediness (potential to spread and survive outside a field trial area) (Bradford et al. 2005), and not on the particular genetic modification techniques used, if any.

It is important to note that the categorization of (GM) varieties, which is based on the identified risk factors and carried out for instance by a panel of experts in the field (see Barton et al. 1997 for an example of how this could be done), should be 
tentative and allow for adjustment as scientific evidence and knowledge accumulates. For example, if clear evidence emerges that compensatory (mitigation) activities could be used (and are de facto available) to substantially reduce the environmental risks of a particular GM variety during field trial, this could prompt a reclassification of the variety into a lower risk category for this phase of its release.

The advantages with this legal solution is its potential to give an overall structure with frames constituting the outer limits at the same time as it contains flexible rules that are better adapted to development of risk assessments for different groups of GMO in the future. This is a legal solution that to some extent promotes the nondiscrimination principle, since it lightens the investigative burdens for GM varieties with lower risk. However, to the extent that it still regulates GM and conventional crops that are phenotypically identical differently, it could be said to violate the non-discrimination principle.

\section{A New Crop Legislation Based on Sustainability Criteria}

A second option could be to abandon the present 'dual-track' system for crop introductions and instead introduce a new crop legislation based on sustainability criteria that apply to all varieties regardless of breeding methods used. That is, instead of focusing on whether a crop has been developed through genetic modification or conventional breeding methods the legislation would departure from the values that are central to achieving a sustainable development within plant breeding. This is a solution in line with the non-discrimination principle but represents an entirely different regulatory logic, since the primary goal of such legislation would no longer be to merely avoid risk and harm but to achieve a broader set of sustainability goals. ${ }^{30}$

From a legal (technical) point of view, a sustainability assessment could be part of the already established legal system for the seed market and its rules of acceptance of varieties. Today, when a genetically modified agricultural variety has fulfilled the requirements for experimental releases in accordance with the Release Directive and it is time to place it on the market, it must be approved and included in a catalogue of varieties in accordance with the Seeds Directive. ${ }^{31}$ The Seeds Directive requires that all varieties that are included in the common catalogue (whether genetically modified or conventional) are distinct, stable, and sufficiently uniform (DUS), and that they have satisfactory value for cultivation and use (VCU). None of these desirable characteristics relates to or are motivated by environmental or health reasons. At present, only genetically modified varieties must in addition to satisfying the DUS and VCU criteria undergo an environmental risk assessment (Seeds Directive, Article 4 and 7). ${ }^{32}$

\footnotetext{
${ }^{30}$ We would like to thank an anonymous reviewer, who pointed this out to us. Comparisons could be made with the Swedish Environmental Code, which contains sustainability criteria that are explicitly referred to in case law (Section 1 of Chapter 1).

31 See footnote 26.

32 The only time when the Seeds Directive mentions environmental and health aspects of conventional varieties is when it is determined that the variety presents a risk for human health and the environment. It
} 
A crop legislation for both conventional and GM varieties based on sustainability criteria should certainly let acceptance depend on the health and environmental risks involved, including indirect and delayed effects. However, it would not discriminate between conventional and GM varieties in this regard. ACRE proposes a similar legal solution with a matrix-based approach in the form of a Comparative Sustainability Assessment which contains ten criteria for assessing sustainability (ACRE 2007): management system and inputs required, persistence and invasiveness, biodiversity, water, soils, energy balance, latency/cumulative effects, reversibility of effects, economic sustainability, and social sustainability.

This legal solution satisfies the principle of non-discrimination. Moreover, it does not prevent inclusiveness of non-safety considerations, such as: Will the variety increase biodiversity, or will it lead to an increased share of monoculture? Will the variety lead to reduced or increased use of pesticides? Can a market introduction be expected to increase or decrease poverty or food safety? Will small farmers be threatened? However, it is more difficult to see how it could incorporate ethical or religious aspects that are not directly related to sustainable development in the assessment, such as naturalness and hubris arguments.

\section{Conclusions}

The analysis in this paper is exploratory and, admittedly, in need of further investigation and justification. First of all, as noted in "What Legal Principles and Criteria Should a Regulatory Framework for GMOs Meet?" section, the legal principles and criteria that we propose are tentative and in need of further elaboration. Specifically, the relationships that hold between the principles (e.g. overlaps and conflicts) require further legal analysis, including analysis of how the principles are interpreted and balanced by, for example, the ECJ. Moreover, the argument developed in "Inclusion of Non-safety Considerations" section, that ethical, religious and socioeconomic aspects, et cetera ought to be part of the approval procedure for GM varieties, would be interesting to analyse further. This involves addressing the question to what extent people's preferences concerning food production, retailing and marketing should be heeded to by governmental decision-makers. It also involves addressing the issue of which ethical demands ought to be addressed in the approval procedure, and which demands can reasonably be met through, for example, labelling requirements. It is not unthinkable that some preferences and values that people might have concerning food production, retailing and marketing, such as a person's preference to consume only non-GM food, could be met through, for example, a rigorous labelling system similar to those in force for Fairtrade products or kosher food. At the same time, however, it is easy to imagine preferences and values that cannot be upheld merely by labelling provisions, such as

Footnote 32 continued

is then permissible for the Member States to prohibit the marketing of seed or propagating material of that variety in all or part of its territory, Article 18. 
a person's preference to restrict GM crop cultivation within the nation's borders on religious or naturalness grounds.

Despite the limited scope of the present analysis a number of conclusions can nevertheless be drawn. First, it is obvious that the EU legislation is discriminatory in the sense that it fails to regulate risk consistently regardless of breeding technique. Moving towards a product-based legislation could be one way of avoiding this inconsistency. However, it could also be argued that one should retain the EU process-based system for GM varieties and instead subject some of the conventionally bread varieties, namely those for which there is reason to believe they involve severe risks to the environment or human health, to a similar risk assessment. The seeds legislation could, for example, be supplemented with such a requirement. However, it remains to be investigated whether this would constitute an economically and administratively feasible solution to the problem.

Second, the scope of the present EU GM legislation is contentious. This is evidenced not the least by the discussion and disagreement surrounding CRISPR/ Cas9 and the other NBTs. However, it is important to keep in mind that regulatory grey zones are widespread in legislation (chemicals legislation is another example in point), although they are of course nevertheless problematic from a legal certainty perspective.

Third, it is difficult to criticize the EU GM legislation for being disproportionate, since proportionality depends on the purpose of the legislation, which, in turn, is a reflection of political values and choices. If the EU legislation were only to be aimed at minimizing risks, had the criticism been able to qualify, since even GM crops with minimal risks are covered by the legislation. But the EU works for a sustainable development of Europe (as well as the Earth) and the Release Directive is based on the precautionary principle and in addition, there are other considerations (non-safety considerations) against the technology that one wants to catch up through legislation (see, for example, Article 3 TEU and Article 11 TFEU). To criticize the EU legislation for being disproportionate therefore requires first a basic discussion on sustainable development and the extent to which the requirements on how to manage uncertainty should be handled otherwise than on the basis of the precautionary principle.

Fourth, there is a certain degree of scientific adaptability in the Release Directive. However, unlike the U.S. legislation, the EU legislation is only adaptable in one direction, that is, in the direction of increased precaution. The reason for this can be traced back to the underlying purpose of the directive, namely to achieve a high level of protection in accordance with the precautionary principle. In our view, this is a weakness of the present EU GM legislation.

Fifth, it is uncertain to what degree the Release Directive really makes room for ethical or socio-economic considerations, since these considerations are not expressed as substantive standards in the directive and the directive is marketbased. The most concrete form of the directive's inclusion of non-safety considerations is in the frame of the newly enacted opt-out procedure, which gives Member States the opportunity to restrict cultivation on, for example, socioeconomic reasons. In the U.S. system, on the other hand, the inclusion of non-safety considerations is, as far as we can see, non-existent. 
So which legal framework is preferable in the end? That question remains to be addressed. From a technical-legal viewpoint, the present paper points at shortcomings in the present EU legislation as regards the criteria of legal certainty, nondiscrimination, and scientific adaptability. These criteria are satisfied to a greater degree in, for instance, the present U.S. product-based system. Conversely, from the viewpoint of non-safety considerations the present EU system appears to be more advantageous. It is easy to associate the different legislative techniques (processbased vs. product-based) with how they are put into practice within the EU and the U.S. However, it should be remembered that the two legislative techniques can be implemented in other ways than what is presently the case on these two continents. For example, there is nothing to prevent taking into account more risk categories (delayed, cumulative et cetera) in the risk assessment before licensing within a product-based system, nor is it impossible to imagine a product-based system that incorporates ethical or socioeconomic aspects to a greater extent than what is presently the case in the U.S. Similarly, one could imagine a process-based legislation that differentiates between investigative requirements based on the properties of the crop under investigation.

Finally, regarding the choice between a process and product-based legislation for GM varieties, it is reasonable to assume that the former will accommodate a greater breadth of preferences and values concerning food production than a product-based system can do. In addition, it might be difficult to meet public requests for product labeling without discriminating the technology as such-and a system in which product labeling does not work would thwart the development of alternative agricultural practices, such as organic farming. However, this should not prevent us from thinking that the EU regulatory system could and should be more finely-tuned so that the investigative requirements are more adapted to the real risks and to the impacts of the new traits themselves.

Acknowledgements The authors would like to thank Professor Jason Czarnezki at Pace University in New York as well as Björn Lundgren and the other participants of the Risk and Safety seminar at the KTH Division of Philosophy, for their valuable comments and suggestions on an earlier version of the article. This research was financed by Mistra-The Swedish Foundation for Strategic Environmental Research. Their support is gratefully acknowledged.

Open Access This article is distributed under the terms of the Creative Commons Attribution 4.0 International License (http://creativecommons.org/licenses/by/4.0/), which permits unrestricted use, distribution, and reproduction in any medium, provided you give appropriate credit to the original author(s) and the source, provide a link to the Creative Commons license, and indicate if changes were made.

\section{References}

Abbott, A. (2015). Europe's genetically edited plants stuck in legal limbo. Nature, 528(7582), 319-320.

ACRE. (2013a). Report 1: Towards an evidence-based regulatory system for GMOs. http://www.defra. gov.uk/acre/files/Report-1.pdf. Accessed September 14, 2016.

ACRE. (2013b). Report 2: Why a modern understanding of genomes demonstrates the need for a new regulatory system for GMOs. http://www.defra.gov.uk/acre/files/Report-2.pdf. Accessed September $14,2016$. 
ACRE (Advisory Committee on Releases to the Environment). (2007). Managing the footprint of agriculture: towards a comparative assessment of risks and benefits for novel agricultural systems. Report of the ACRE Sub-Group on Wider Issues raised by the Farm-Scale Evaluations of Herbicide Tolerant GM Crops. http://webarchive.nationalarchives.gov.uk/20080727101330/http:/www.defra. gov.uk/environment/acre/fsewiderissues/pdf/acre-wi-final.pdf. Accessed September 14, 2016.

Barton, J., Crandon, J., Kennedy, D., \& Miller, H. (1997). A model protocol to assess the risks of agricultural introductions. Nature Biotechnology, 15(9), 845-848.

Batista, R., Saibo, N., Lourenço, T., \& Oliveira, M. M. (2008). Microarray analyses reveal that plant mutagenesis may induce more transcriptomic changes than transgene insertion. Proceedings of the National Academy of Sciences of the United States of America, 105(9), 3640-3645.

Bradford, K. J., Van Deynze, A., Gutterson, N., Parrott, W., \& Strauss, S. H. (2005). Regulating transgenic crops sensibly: Lessons from plant breeding, biotechnology and genomics. Nature Biotechnology, 23(4), 439-444.

Camacho, A., Van Deynze, A., Chi-Ham, C., \& Bennett, A. B. (2014). Genetically engineered crops that fly under the US regulatory radar. Nature Biotechnology, 32(11), 1087-1091.

Czarnezki, J., \& Montgomery, E. (2013). Genetically modified organisms and the environment. In M. J. Angelo, J. J. Czarnezki, \& W. S. Eubanks II (Eds.), Food, agriculture and environmental law (pp. 93-112). Washington, DC: Environmental Law Institute.

de Sadeleer, N. (2015). Marketing and cultivation of GMOs in the EU. European Journal of Risk Regulation, 6, 532-558.

Douglas, H. (2009). Science, policy, and the value-free ideal. Pittsburgh: University of Pittsburgh Press.

Du, D. (2012). Rethinking risks: Should socioeconomic and ethical considerations be incorporated into the regulation of genetically modified crops? Harvard Journal of Law and Technology, 26(1), 375-401.

Ebbesson, J. (2009). The rule of law in governance of complex socio-ecological changes. Global Environmental Change, 20(3), 414-422.

Falck-Zepeda, J. B. (2009). Socio-economic considerations, Article 26.1 of the Cartagena Protocol on Biosafety: What are the issues and what is at stake? AgBioForum, 12(1), 90-107.

Falck-Zepeda, J. B., \& Zambrano, P. (2011). Socio-economic considerations in biosafety and biotechnology decision making: The Cartagena Protocol and national biosafety frameworks. Review of Policy Research, 28(2), 171-195.

Giddings, L. V., Potrykus, I., Ammann, K., \& Fedoroff, N. V. (2012). Confronting the Gordian knot. Nature Biotechnology, 30(3), 208-209.

Hartung, F., \& Schiemann, J. (2014). Precise plant breeding using new genome editing techniques: Opportunities, safety and regulation in the EU. The Plant Journal, 78(5), 742-752.

Heap, B. (2013). Europe should rethink its stance on GM crops. Nature, 498(7455), 409.

Jaffe, G. (2004). Regulating transgenic crops: A comparative analysis of different regulatory processes. Transgenic Research, 13(1), 5-19.

Jans, J. H., \& Vedder, H. H. B. (2012). European environmental law after Lisbon. Groningen: Europa Law Publishing.

Jones, H. D. (2015). Regulatory uncertainty over genome editing. Nature Plants, 1, 1-3.

Kimbrell, G. A. (2013). Regulating transgenic crops pursuant to the Plant Protection Act. In M. J. Angelo, J. J. Czarnezki, \& W. S. Eubanks II (Eds.), Food, agriculture, and environmental law (pp. 281-300). Washington, DC: Environmental Law Institute.

Kysar, D. A. (2004). Preferences for processes: the process/product distinction and the regulation of consumer choice. Harvard Law Review, 118(2), 525-642.

Levidow, L., Murphy, J., \& Carr, S. (2007). Recasting "substantial equivalence": Transatlantic governance of GM food. Science, Technology and Human Values, 32(1), 26-64.

Ludlow, K., Smyth, S. J., \& Falck-Zepeda, J. (2014). Introduction to socio-economic considerations in the regulation of genetically modified organisms. In K. Ludlow, S. J. Smyth, \& J. Falck-Zepeda (Eds.), Socio-economic considerations in biotechnology regulation (pp. 3-14). New York: Springer.

Macdonald, P. (2014). Genetically modified organisms regulatory challenges and science: A Canadian perspective. J. Verbr. Lebensm., 9(Suppl 1), S59-S64.

Marchant, G., Meyer, A., \& Scanlon, M. (2010). Integrating social and ethical concerns into regulatory decision-making for emerging technologies. Minnesota Journal of Law, Science and Technology, 11(1), 345-363.

Marchant, G. E., \& Stevens, Y. A. (2015). A new window of opportunity to reject process-based biotechnology regulation. GM Crops \& Food, 6(4), 233-242. 
Marcoux, J.-M., Cardenas Gomez, O. C., \& Létourneau, L. (2013). The inclusion of nonsafety criteria within the regulatory framework of agricultural biotechnology: Exploring factors that are likely to influence policy transfer. Review of Policy Research, 30(6), 657-684.

Marcusson, L. (2012). Principer inom den offentliga rätten. In L. Marcusson (Ed.), Offentligrättsliga principer (pp. 9-15). Uppsala: Iustus.

Masip, G., Sabalza, M., Pérez-Massot, E., Banakar, R., Cebrian, D., Twyman, R. M., et al. (2013). Paradoxical EU agricultural policies on genetically engineered crops. Trends in Plant Science, 18(6), 312-324.

McHughen, A. (2007). Fatal flaws in agbiotech regulatory policies. Nature Biotechnology, 25(7), 725-727.

McHughen, A., \& Smyth, S. (2008). US regulatory system for genetically modified [genetically modified organism (GMO), rDNA or transgenic] crop cultivars. Plant Biotechnology Journal, 6(1), 2-12.

Miller, H. I. (2010). The regulation of agricultural biotechnology: Science shows a better way. New Biotechnology, 27(5), 628-634.

Miller, H. I., Altman, D. W., Barton, J. H., \& Huttner, S. L. (1995). An algorithm for the oversight of field trials in economically developing countries. Nature Biotechnology, 13, 955-959.

Millstone, E., Brunner, E., \& Mayer, S. (1999). Beyond 'substantial equivalence'. Nature, 401, 525-526.

Morris, S. H. (2007). EU biotech crop regulations and environmental risk: A case of the emperor's new clothes? Trends in Biotechnology, 25(1), 2-6.

Morris, S. H., \& Spillane, C. (2010). EU GM crop regulation: a road to resolution or a regulatory roundabout. EJRR, 4, 359-369.

NIH. (1992). National biotechnology policy board report. Bethseda, MD: National Institutes of Health. OECD. (1993). Safety evaluation of foods derived by modern biotechnology. Paris: OECD.

Podevin, N., Devos, Y., Davies, H. V., \& Nielsen, K. M. (2012). Transgenic or not? No simple answer! New biotechnology-based plant breeding techniques and the regulatory landscape. EMBO Reports, 13(12), 1057-1061.

Pouteau, S. (2002). The food debate: Ethical versus substantial equivalence. Journal of Agricultural and Environmental Ethics, 15(3), 289-303.

Riviere, J. E., \& Buckley, G. J. (Eds.). (2012). Ensuring safe foods and medical products through stronger regulatory systems abroad. Washington, DC: The National Academies Press.

Sagers, C. L., \& Finlay, R. (2013). Erring on the side of caution: a case for increased regulatory oversight of genetically modified organisms in the United States. In Scientific conference 2012: Advancing the understanding of biosafety-GMO risk assessment, independent biosafety research and holistic analysis, European network of scientists for social and environmental responsibility, third world network and Tara Foundation (pp. 81-91).

Smyth, S., \& McHughen, A. (2008). Regulating innovative crops technologies in Canada: The case of regulating genetically modified crops. Plant Biotechnology Journal, 6(3), 213-225.

Then, C. (2013). Analysis of risk assessment strategies for genetically engineered plants used for food and feed in the EU. In Scientific conference 2012: Advancing the understanding of biosafety-GMO risk assessment, independent biosafety research and holistic analysis, European network of scientists for social and environmental responsibility, third world network and Tara Foundation (pp. 46-51).

Valve, H., \& Kauppila, J. (2008). Enacting closure in the environmental control of genetically modified organisms. Journal of Environmental Law, 20(3), 339-362.

von Kries, C., \& Winter, G. (2012). The structuring of GMO release and evaluation in EU law. Biotechnology Journal, 7(4), 569-581.

Winter, G. (2013). Ecological proportionality: An emerging principle of law for nature? In C. Voigt (Ed.), Rule of law for nature: New dimensions and ideas in environmental law (pp. 111-129). New York: Cambridge University Press.

Winter, G. (2015) Nationale Anbaubeschränkungen und-verbote für gentechnisch veränderte Pflanzen und ihre Vereinbarkeit mit Verfassungs-, Unions- und Völkerrecht. Rechtsgutachten im Auftrag des Bundesamtes für Naturschutz, Mai 2015. Universität Bremen. http://www.bfn.de/fileadmin/BfN/ recht/Dokumente/Opt_Out_RGutachten_Winter.pdf. Accessed September 14, 2016.

Winter, G. (2016). Cultivation restrictions for genetically modified plants: On variety of risk governance in European and international trade. EJRR, 7(1), 120-143. 